\title{
Rancang Bangun Tracker Surya Sumbu Ganda Berbasis Raspberry Pi
}

\author{
M Permadi Yosa Nugraha1, Abdul Rakhman², Irma Salamah ${ }^{3}$ \\ 1,2,3 Jurusan Teknik Elektro, Program Studi Teknik Telekomunikasi Politeknik Negeri Sriwijaya \\ 1permadiyosa@gmail.com, 2arrakhman77@gmail.com,3irma.salamah@yahoo.com
}

\begin{abstract}
Solar energy is now a very important means of renewable energy resources. With sun tracking, it is more effective to produce more energy because solar panels can maintain a profile perpendicular to sunlight. Although the initial cost of setting up a tracking system is quite high, there are cheaper options that have been proposed from time to time. Light Dependent Resistors (LDRs) are used to detect sunlight. The solar panel is positioned where it can receive maximum light. Compared to other motors, servo motors are able to maintain torque at high speed. The tracker is in the form of a double or single axis. Dual trackers are more efficient because they track sunlight from both axes. This project is designed for low power and portable applications. Therefore, it is suitable for use in rural areas. In addition, the effectiveness of the output power collected by sunlight increases.
\end{abstract}

Keywords: Servo Motor, Solar, Raspberry Pi, Drivers, LDR Sensors

\begin{abstract}
Abstrak
Energi surya saat ini menjadi sarana sumber daya energi terbarukan yang sangat penting. Dengan pelacakan matahari, akan lebih efektif untuk menghasilkan lebih banyak energi karena panel surya dapat mempertahankan profil tegak lurus terhadap sinar matahari. Meskipun biaya awal untuk menyiapkan sistem pelacakan cukup tinggi, ada opsi yang lebih murah yang telah diusulkan dari waktu ke waktu. Light Dependent Resistors (LDRs) digunakan untuk mendeteksi sinar matahari. Panel surya diposisikan di mana ia dapat menerima cahaya maksimum. Dibandingkan dengan motor lain, motor servo mampu mempertahankan torsi dengan kecepatan tinggi. Pelacak tersebut berupa sumbu ganda atau tunggal. Pelacak ganda lebih efisien karena mereka melacak sinar matahari dari kedua sumbu. Proyek ini dirancang untuk daya rendah dan aplikasi portabel. Karena itu, cocok untuk penggunaan di daerah pedesaan. Selain itu, efektivitas daya output yang dikumpulkan oleh sinar matahari lebih besar.
\end{abstract}

Kata Kunci: Servo Motor, Solar, Raspberry Pi, Driver, Sensor LDR

\section{PENDAHULUAN}

Dalam kurun waktu adanya peningkatan permintaan untuk energi listrik yang dapat diandalkan dan berlimpah yang berasal dari sumber energi terbarukan energi terbarukan memainkan peran penting dalam krisis energi negara. Pemerintah mulai mengurangi penggunaan sumber energi konvensional dan mendorong orang untuk menggunakan sumber energi terbarukan seperti air dan matahari. Salah satu contoh dari energi terbarukan adalah tenaga surya. Energi matahari adalah sumber energi yang sangat besar dan tak pernah habis. Pelacak surya adalah perangkat yang digunakan untuk mengarahkan panel surya 
fotovoltaik untuk memusatkan reflektor matahari atau lensa ke arah matahari. Dalam proyek ini, dibagi oleh dua kategori; perangkat keras dan perangkat lunak. Di bagian perangkat keras, light dependent resistor (LDR) telah digunakan untuk melacak sinkronisasi sinar matahari dengan mendeteksi tingkat kecerahan sinar matahari. Untuk bagian rotasi, motor servo standar adalah solusinya. Di bagian perangkat lunak, kode ini dibangun dalam pemrograman Python dan dimasukkan dalam Raspberry Pi. Proyek ini dirancang untuk daya rendah dan aplikasi portabel. Karena itu, cocok untuk penggunaan di daerah pedesaan. Maka dari itu diperlukan tracker surya sumbu ganda yang portable.

[1] "Arduino Berbasis Dua Sumbu Surya Pelacakan dengan Menggunakan Mekanisme Servo" V.Brahmeswara Rao, K.Durga Harish Kumar, NVUpendra Kumar, K.Deepak makalah ini menyebutkan tentang sumber energi tak terbarukan seperti batu bara dan minyak memadamkan dan sehingga menjadi masalah serius untuk menyediakan energi yang andal kepada dunia. Dalam proyek ini kami mengusulkan sistem pelacakan surya sumbu ganda yang memungkinkan untuk menangkap jumlah maksimum energi matahari dengan menggunakan Arduino sebagai unit pemrosesan utama.

[2] "Merancang Sistem Pelacakan Matahari Sumbu Ganda untuk Daya Maksimum" Vijayalakshmi K Sebutan Tujuan utama dari makalah ini adalah untuk menyajikan sistem kontrol yang akan menyebabkan penyelarasan lebih baik dari array Photo voltaic (PV) dengan sinar matahari, Sistem yang diusulkan mengubah arahnya dalam dua sumbu untuk melacak koordinat sinar matahari dengan mendeteksi perbedaan antara posisi matahari dan panel. Pengujian perangkat keras dari sistem yang dilakukan untuk memeriksa kemampuan sistem untuk melacak dan mengikuti sinar matahari dengan Dual axis solar tracking system superioritas atas sistem pelacakan matahari sumbu tunggal juga disajikan.

[3] "Pelaksanaan pelacak matahari menggunakan arduino dengan servo motor" P.Ramya1, R.Ananth Tujuan dari makalah ini adalah untuk mengkonsumsi energi matahari maksimum melalui panel surya. A Solar Tracker adalah perangkat di mana panel surya built-in yang melacak gerakan matahari memastikan bahwa jumlah maksimum sinar matahari menyerang panel sepanjang hari. Output daya dari sel surya akan menjadi maksimum ketika menghadap matahari yaitu sudut antara permukaan dan sinar matahari adalah 90 derajat. Pelacakan surya memungkinkan lebih banyak energi untuk diproduksi karena array surya mampu tetap sejajar dengan matahari. Komponen yang digunakan untuk konstruksi adalah motor servo, Arduino dan LDR. Sensor aktif secara terus menerus memantau sinar matahari dan mengganti panel ke arah mana intensitas sinar matahari maksimum.

[4] "Pelacak surya untuk panel surya" Oloka Reagan Otieno makalah ini menyebutkan Dalam proyek ini sistem pelacakan matahari sumbu tunggal telah dikembangkan. Dalam proyek ini, Arduino Uno telah digunakan sebagai unit pengendali utama. Untuk mendeteksi posisi matahari di langit, dua LDR telah digunakan dan untuk memutar orientasi panel PV Surya motor servo telah digunakan. Sensor dan motor servo telah benar-benar dihubungkan dengan papan Arduino. Motor servo telah secara mekanis digabungkan dengan panel PV. 
Program mengemudi telah ditulis menggunakan Arduino IDE. Pelacak ini mengubah arah panel surya berdasarkan arah matahari yang menghadap ke panel dengan sumbu tunggal melacak matahari setiap hari dan membuat panel surya lebih efisien.

\section{METODE PENELITIAN}

Rancang bangun peralatan merupakan hal yang sangat pokok dalam pembuatan tugas akhir ini. Tahap perencanaan merupakan perwujudan awal dari pembuatan tugas akhir ini. Dalam tahap ini akan meliputi beberapa langkah perancangan hingga terwujudnya satu kesatuan sesuai dari hasil rancangan yang diinginkan. Di dalam melakukan perancangan sangat diperlukan buku-buku petunjuk yang berkaitan dengan perancangan alat yang akan dibuat sehingga pada akhirnya pembuatan suatu perangkat elektronik dilakukan perancangan terhadap benda kerja maka terlebih dahulu dipersiapkan suatu perencanaan yang baik untuk mendapatkan hasil yang memuaskan. Dalam pembuatan alat dalam penelitian ini diselesaikan dengan langkah kerja yaitu diperoleh hasil perancangan yang baik.

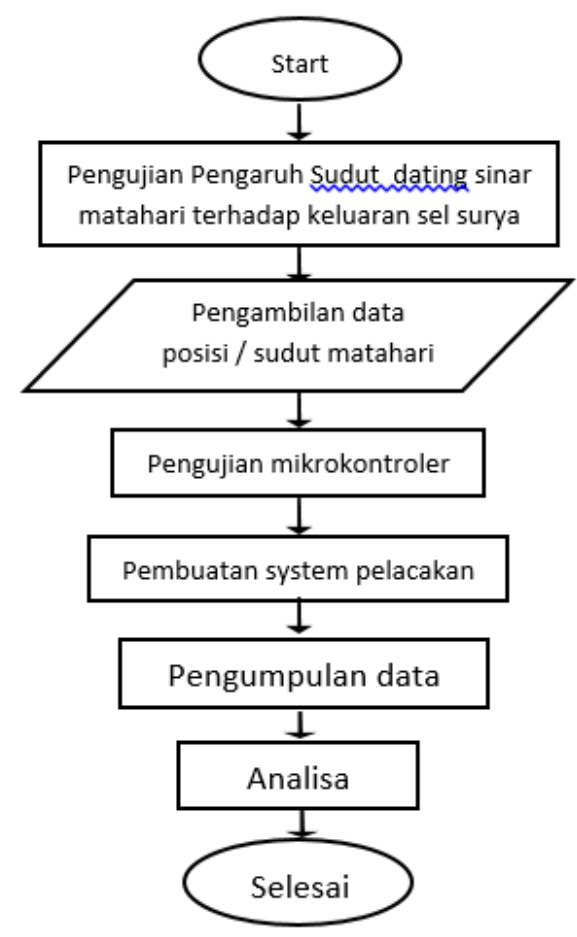

Gambar 1. Diagram Blok Langkah Penelitian 


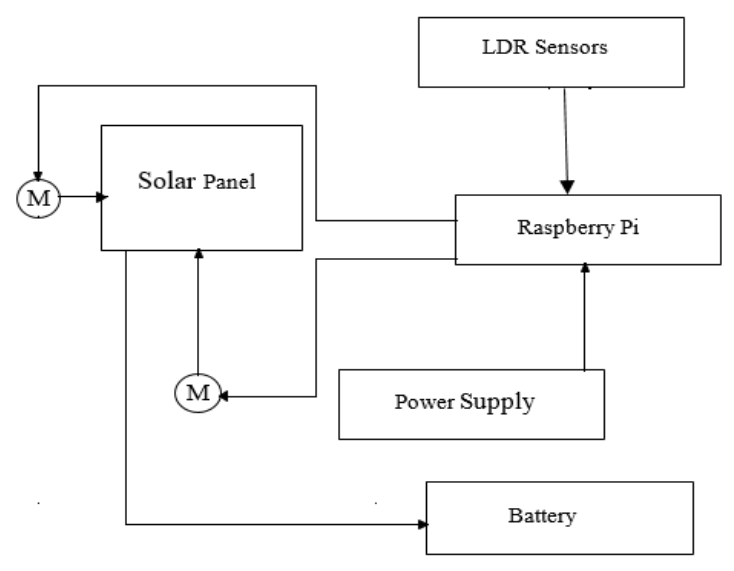

Gambar 2. Blog Diagram Sistem

Perancangan alat ini dibuat secara portable salah satu bagian terpenting dalam perancangan alat ini. Dari blok diagram maka dapat diketahui prinsip kerja rangkaian keseluruhan. Sel surya pada Pelacakan Matahari menggunakan Raspberry $\mathrm{Pi}$, di mana kita akan menggunakan LDR untuk mendeteksi tingkat intensitas cahaya pada matahari yang besar sedangkan Motor Servo untuk menggerakkan rangkaian alat secara otomatis untuk memutar sel surya ke arah paparan sinar matahari secara langsung. Selain itu dari bagian Raspberry Pi yang berperan sebagai main controling memprogram untuk memproses data yang diinput dari besarnya tingkat intensitas cahaya yang didapat pada sensor ldr selanjutnya memberikan command untuk menggerakkan rangkaian alat dengan menggunakan motor servo. Sehingga alat ini dapat bekerja mengikuti cahaya matahari dengan intensitas yang tinggi dan selalu menghadap ke arah matahari secara langsung untuk mendapatkan muatan daya sepanjang waktu.

\section{HASIL DAN PEMBAHASAN}

Pada penelitian ini dirancang alat tracker surya sumbu ganda dengan menggunakan raspberry pi untuk daya rendah dan aplikasi portabel. Karena itu, alat cocok untuk penggunaan di daerah pedesaan. Selain itu, efektivitas daya output yang dikumpulkan oleh sinar matahari lebih besar.

\subsection{Tampilan Hasil Perancangan}

Pada tampilan hasil perancangan alat tracker beserta komponennya ini telah dirangkai Komponen yang digunakan dalam perancangan berupa Sensor $L D R$, Motor Servo, Raspberry Pi, Solar, Resistor, Battre, Jumper secukupnya dan USB sebagai komponen pendukung. Alat ini menggukan Power Supply sebagai catu dayanya. Tampilan alat Tracker Surya sebagai berikut: 

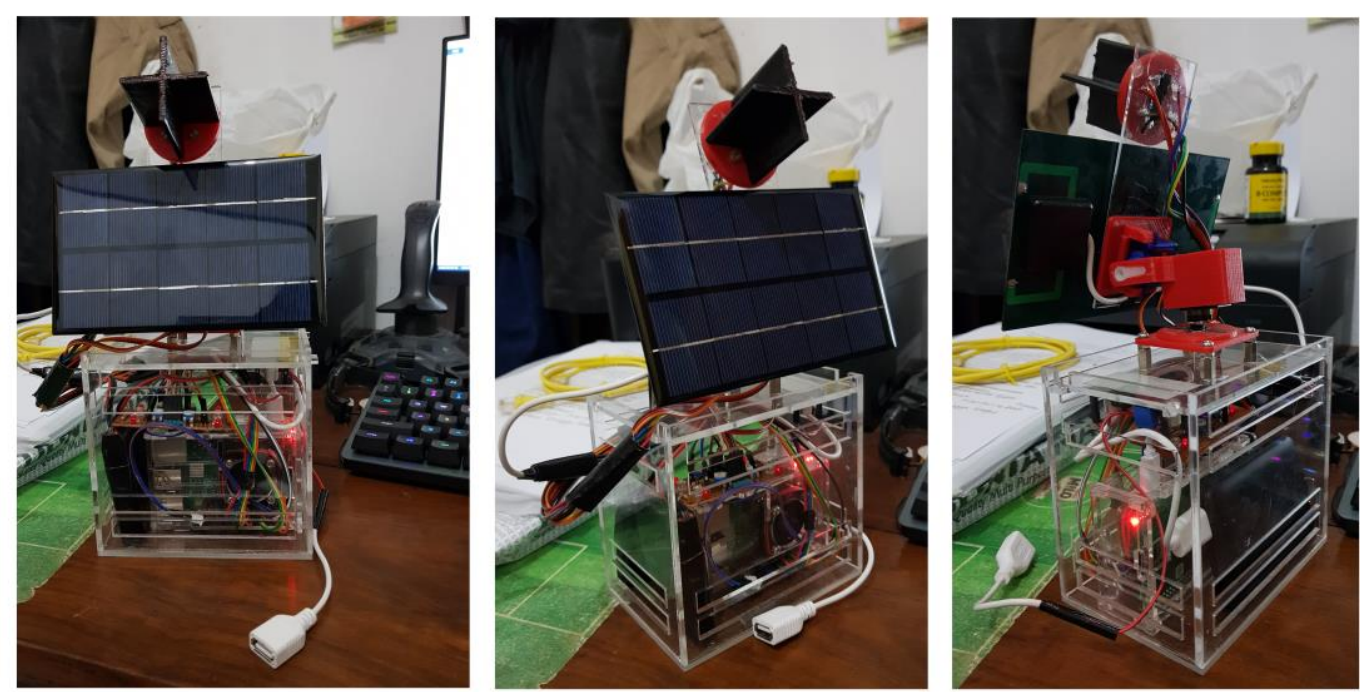

Gambar 3. Tampilan Alat Tracker Surya

\subsection{Pola pergerakan}

Didapatlah hasil pergerakan alat yang bergerak mengikuti arah cahaya pada matahari atau sensor yang bergerak secara langsung mengikuti cahaya pada sinar matahari tersebut, pada sensor tersebut didapatlah hasil pola perhitungan pergerakan dengan sensor secara satu persatu maupun secara keseluruhan pada keempat sensor tersebut, ada sebagian dan beberapa dari sensor diberi warna putih dikarenakan intensitas cahaya matahari yang diterima besar sedangkan sebagian yang berwarna gelap dikarenakan intensitas cahaya matahari yang diterima kecil. Berikut adalah pola pada sensor LDR

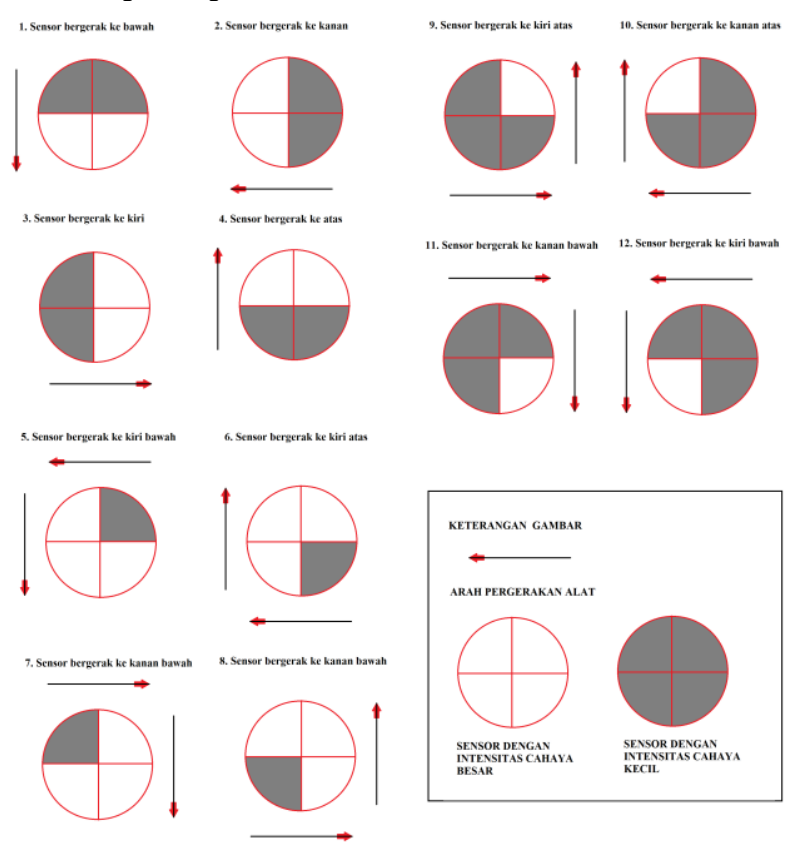

Gambar 4. Pola Pergerakan

Rancang Bangun Tracker Surya Sumbu Ganda Berbasis Raspberry Pi (M Permadi Yosa Nugraha)| 86 


\section{Pengujian Kerja Alat}

Pengujian kerja alat tracker surya sumbu ganda atau dual axis XY yaitu $X$ sebagai Vertikal dan Y sebagai Horizontal dengan rentang waktu 06:00 - 16:30 sebagai berikut:

1. Hasil pengujian pada saat pergerakan sumbu Vertikal ( $X$ ) pada pukul 06:30 - 16:30 didapatlah hasil sebagai berikut:

Tabel 1. Hasil Pengujian Sumbu Vertikal

\begin{tabular}{|c|c|c|}
\hline No & Pukul & Derajat \\
\hline 1 & $06: 30$ & $19^{\circ}$ \\
\hline 2 & $08: 30$ & $38^{\circ}$ \\
\hline 3 & $10: 30$ & $63^{\circ}$ \\
\hline 4 & $12: 30$ & $7^{\circ}$ \\
\hline 5 & $14: 30$ & $55^{\circ}$ \\
\hline 6 & $16: 30$ & $25^{\circ}$ \\
\hline
\end{tabular}

2. Hasil pengujian pada saat pergerakan sumbu Horizontal ( $Y$ ) pada pukul 06:30 - 16:30 didapatlah hasil sebagai berikut:

Tabel 2. Hasil Pengujian Sumbi Horizontal

\begin{tabular}{|c|c|c|}
\hline No & Pukul & Derajat \\
\hline 1 & $06: 30$ & $95^{\circ}$ \\
\hline 2 & $08: 30$ & $142^{\circ}$ \\
\hline 3 & $10: 30$ & $155^{\circ}$ \\
\hline 4 & $12: 30$ & $186^{\circ}$ \\
\hline 5 & $14: 30$ & $214^{\circ}$ \\
\hline 6 & $16: 30$ & $235^{\circ}$ \\
\hline
\end{tabular}

3. Hasil pengujian pada saat pergerakan sumbu Diagonal ( $\mathrm{XY}$ ) pada pukul 06:30 - 16:30 didapatlah hasil sebagai berikut:

Tabel 3. Hasil Pengujian Sumbu Diagonal

\begin{tabular}{|c|c|c|c|}
\hline \multirow{2}{*}{ No } & \multirow{2}{*}{ Pukul } & \multicolumn{2}{|c|}{ Derajat } \\
\cline { 3 - 4 } & & $\mathbf{X}$ & $\mathbf{Y}$ \\
\hline 1 & $06: 30$ & $19^{\circ}$ & $9^{\circ}$ \\
\hline 2 & $08: 30$ & $38^{\circ}$ & $142^{\circ}$ \\
\hline 3 & $10: 30$ & $63^{\circ}$ & $155^{\circ}$ \\
\hline 4 & $12: 30$ & $70^{\circ}$ & $186^{\circ}$ \\
\hline 5 & $14: 30$ & $55^{\circ}$ & $214^{\circ}$ \\
\hline 6 & $16: 30$ & $25^{\circ}$ & $235^{\circ}$ \\
\hline
\end{tabular}




\section{KESIMPULAN}

Pelacak surya sumbu ganda yang diusulkan secara otomatis melacak posisi matahari dan memaksimalkan tenaga surya dengan bantuan Raspberry Pi. Dibandingkan dengan sumbu tunggal, sistem sumbu ganda memberikan output energi listrik yang melimpah tinggi jika dibandingkan dengan sistem pemasangan tetap. Pelacak sumbu ganda memiliki lebih banyak efisiensi. Tujuan utama dari pekerjaan ini adalah untuk mengembangkan sistem pelacak surya dua sumbu dengan menggunakan empat sensor (ldr) sebagai input intensitas cahaya matahari yang besar untuk memprediksi posisi pada matahari.

Maka dengan menggunakan sensor LDR sebagai penentu arah dari besarnya intensitas cahaya yang dipancarkan oleh sinar matahari dan pada Motor Servo sebagai alat penggerak arah kepada sinar matahari, kedua alat tersebut saling berkesinambungan satu sama lain dengan menggunakan Raspberry Pi sebagai main control pada rancang bangun tracker surya sumbu ganda.

\section{DAFTAR PUSTAKA}

[1] V.Brahmeswara Rao, K.Durga Harish Kumar, V.Upendra Kumar and K.Deepak, "Arduino Based Two Axis Solar Tracking by Using Servo Mechanism”, IEEE Te Technol., Vol. 03, no. 02, 2017, pp. 41-44.

[2] Vijayalakshmi K "Designing a Dual Axis Solar Tracking System for Maximum Power" J Electr Electron Syst 2016

[3] P.Ramya, R.Ananth "The implementation of solar tracker using arduino with servomotor" Volume: 03 no: 08 Aug2016.

[4] Oloka Reagan Otieno "Solar tracker for solar panel" no: F17 24 April, 2015 